\title{
REAL-TIME SIMULATED EARTHQUAKE MOTION OF HIGH RISE STRUCTURES
}

\author{
James Lord*
}

\section{SYNOPSIS}

The real-time simulation of a high rise structure during an earthquake represents a marked step forward in the structural design field. It affords a graphic display of the dynamic behaviour and characteristics of such a structure. The simulation can be presented on a CRT or by means of a 16 or $35 \mathrm{~mm}$. movie and tailored for client or technical viewing.

\section{INTRODUCTION}

This paper discusses the application of the computer techniques involved in dynamically analysing and simulating the seismic response of an actual 52 story steel-framed tower located in the Los Angeles area. The tower was modelled mathematically and excited by several earthquakes. A dynamic analysis obtained the time history of the responses and ground motion. The combined response for the 1940 E1 Centro ( $\mathrm{N}-\mathrm{S}$ component) earthquake was then simulated in real-time on a CRT and the motion of the tower recorded on a $16 \mathrm{~mm}$. movie. This seven minute movie portrays several sequences of the combined seismic response at scale factors noted in parenthesis, including;

1. Ground motion (x 120) plus actual building response for the first eight modes of vibration.

2. Combined ground and building motion of the first eight modes ( $x$ 120).

3. Coincidental modal responses of the first three modes of vibration ( $x$ 67), including ground motion. These individual modal responses were isolated and displayed as three separate images on each frame of the sequence.

4. An interrupt sequence of 3. Several stop frames have been introduced to illustrate certain dynamic characteristics.

5. Repeat of sequence 2 .

The paper comprises;

- A general discussion of the state of the * Principal Systems Engineer, Albert C. Martin and Associates, Los Angeles, California. art of dynamic analysis as related to buildings and building codes. Direct integration, normal mode, and modal superposition - response spectra methods are reviewed;

- A description of the analysis phase, including a detailed look at the computer programs used;

- An outline of the post-analysis procedures, discussing the techniques involved in simulating the building motion first on the CRT and then on film. The out-line includes a brief description of the software package and the hardware configuration utilized.

- An evaluation of the analysis and simulation is made. The paper contains several beforeafter portrayals of the maximum responses of the structure, illustrating how certain undesirable dynamic characteristics were in fact controlled.

\section{DYNAMIC ANALYSIS - GENERAL REVIEW}

Basically there are three categories or types of dynamic analysis.

1. Direct integration of the general equations of motion.

2. Normal mode analysis.

3. Response spectra techniques.

1. The direct integration method is a perfectly general technique. It is applicable to coupled, uncoupled, elastic or inelastic systems vibrating under any loading configuration. For a multi-degree of freedom system, subject to support motion, we have in matrix notation;

$$
[M]\{\dot{y}\}+[c]\{\dot{u}\}+[K]\{u\}=0
$$

Where

[M] = diagonal matrix of successive story masses for a lumped mass analysis.

[C] = damping coefficient matrix

$[\mathrm{K}]=$ lateral stiffness matrix 
96

$\{\ddot{y}\}=$ absolute acceleration vector

$\{\dot{i}\},\{\dot{u}\},\{u\}=$ relative to base lateral

acceleration, velocity and displacement vectors respectively

Since $\{\ddot{y}\}=\{\ddot{u}\}+\ddot{y}_{S}$ by definition

Back substituting in the general equation of motion

We have $[M]\{\ddot{u}\}+[C]\{\dot{u}\}+[K]\{u\}=-\{M\} \ddot{y}_{S}$

Where

$\{M\}=$ vector of successive story masses

$\ddot{y}_{S}(t)=$ time varying ground acceleration

Direct integration of this latter equation of motion yields the lateral accelerations and displacements story by story from which all joint deformations and rotations, story shears and overturning moments and member stress levels can be obtained.

2. The normal mode method is a limited technique. It is applicable only to linear elastic systems vibrating under the action of loads having a common time function. These limitations allow any close or far coupled system to be uncoupled and treated as several independent single degree of freedom systems. This is to say that all the modes of vibration are independent of each other.

For the $n^{\text {th }}$ mode, the modal equation of motion is:

$\ddot{A}_{n}+2 w_{n} c_{n} \dot{A}_{n}+w_{n}^{2} A_{n}=-\ddot{y}_{s}(t) \quad \sum_{r=1}^{j} \emptyset_{r n} M_{r}$

Where

$\mathrm{W}_{\mathrm{n}}$ = natural circular frequency of vibration for the $\mathrm{n}^{\text {th }}$ mode $\mathrm{C}_{\mathrm{n}}=\underset{\text { fraction of }}{\text { mode }}$ critical damping in the $\mathrm{n}^{\text {th }}$

$\ddot{A}_{\mathrm{n}}, \dot{\mathrm{A}}_{\mathrm{n}}, \mathrm{A}_{\mathrm{n}}=$ modal amplitudes of acceleration, velocity and displacement for the $n^{\text {th }}$ mode, relative to base.

$\ddot{y}_{S}(t)=$ time varying ground acceleration

$\mathrm{M}_{r}=r^{\mathrm{th}}$ mass

$\emptyset_{\mathrm{rn}}=$ normalized characteristic displacement at the $r^{\text {th }}$ mass for the $n^{\text {th }}$ mode.

$j=$ total number of masses (stories) in

structure.

$y$ integrating the above modal equation for each of the modes to be considered ana, sumusis each response parameter $\ddot{A}_{\mathrm{n}}, \dot{A}_{\mathrm{n}}, \mathrm{A}_{\mathrm{n}}$ in normal coordinates, the response parameters $y, y \& y$ can be obtained by the modal relationship $\ddot{y}=\Phi A_{n}$ etc.

Where

$\Phi=$ square matrix containing all the normalized eigenvectors such that the $n^{\text {th }}$ column corresponds to the $\mathrm{n}^{\text {th }}$ mode.

Hence the remaining essential response parameters can be computed directly.

3. A response spectrum is a plot of the maximum value of any response parameter against the period of vibration for a linear elastic single degree of freedom system. Figure 1 shows a typical response spectrum for the pseudovelocity (a 5\% damping for the $A 1, A 2$ and the 1940 E1 Centro (NS component) earthquakes. Relative displacements and hence stress levels can be expressed in terms of the velocity spectrum through simple relationships. For simple structures such as elevated water tanks, response spectra can be used directly to obtain the structural response. For complicated structures, in which the contribution of higher modes of vibration are significant, the accurate prediction of maximum values of any response parameter is extremely difficult. This is because the time at which the maximum response occurs is not preserved in the spectral curves and since the maximum values of the individual modes do not necessarily occur simultaneously, the phase relationship between the maxima are lost, and hence the exact way in which the various modes combine cannot be determined. Several approximate methods of mode combination have been suggested, ranging from simply taking the sum of the absolute values (Biot 1943) to taking the weighted average of the square root of the sum of the squares of the maximum individual modal responses. (Hudson $\&$ Merchant 1962) $)^{1}$. The former method obviously would give the worst case and merely sets an upper bound. Even the refinements of the latter method have some limitations as pointed out by Shepard ${ }^{2}$. It should be noted that the use of any response spectra requires an accurate knowledge of the natural periods and mode shapes.

The state of the art of dynamic analysis as related to buildings in particular, is one of fast development. Wind dynamics and earthquake engineering have become major considerations to the structural engineer. He is aware of the inadequacies of the code static analysis approaches. The large digital computer is now his tool in solving the dynamics problem. He is able to utilize all the three types of dynamic analysis outlined earlier. Computer technology has stimulated the use of the direct integration and normal 


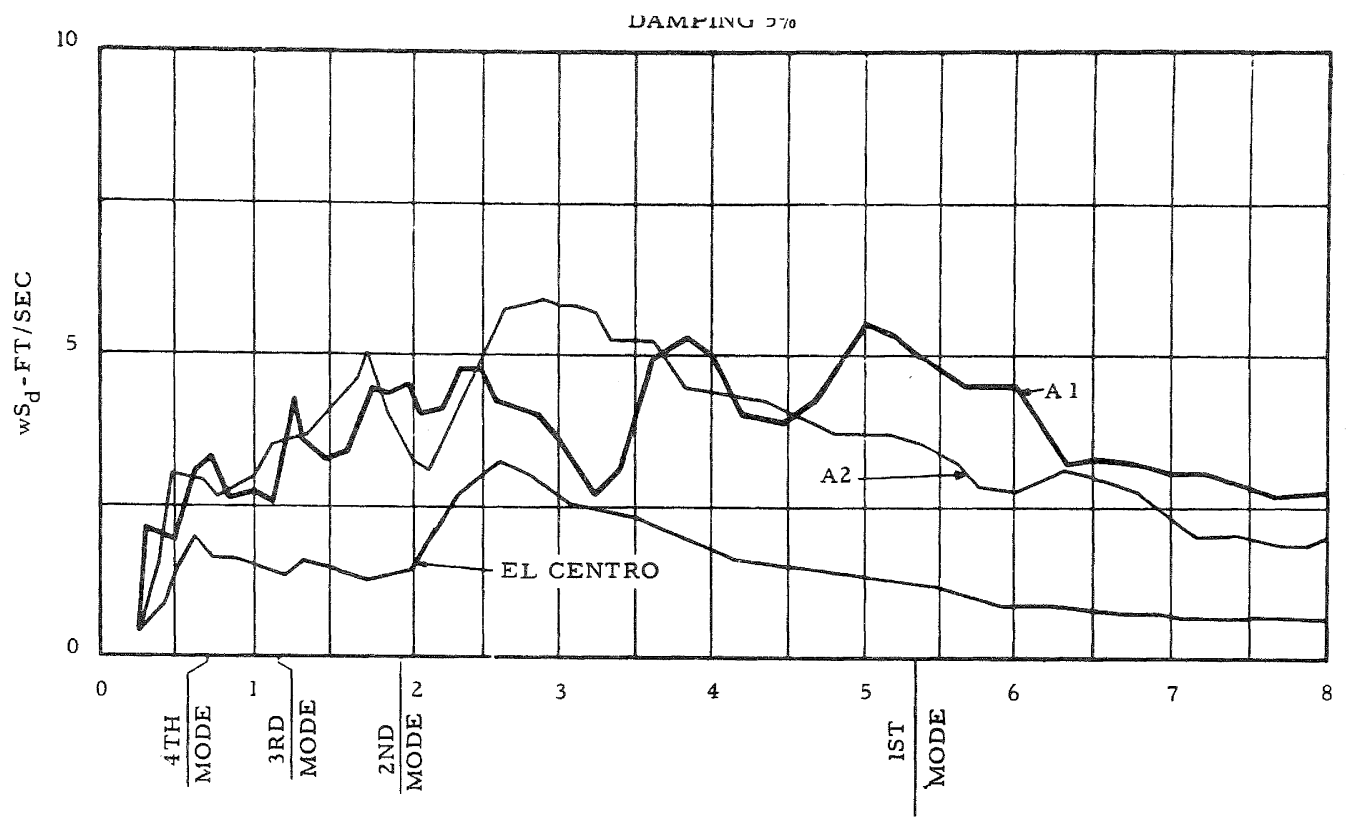

FIGURE 1

VELOCITY SPECTRUM

mode analysis methods. In general, response spectra techniques are not used to predict responses, but serve to correlate computed elastic response calculations. They are used, for instance, to determine the desired length of earthquake record to be used in a normal mode or step-by-step integration solution. Spectral techniques also have been very effective in establishing trends in linear responses of tall buildings to earthquake motion ${ }^{3}$.

\section{ANALYSIS PHASE}

\section{General}

The generation of the time history of the building response including individual modal participation and the ground motion history comprised the analysis phase. Reference to Figure $2 a$ will indicate that two computer programs "ACMDYN"4 and "EQGRMO"5 and a $131 \mathrm{k}$ Univac 1108 hardware configuration were used to implement this phase.

\section{Description of Structure}

The 52 story, steel-framed tower was modelled mathematically and excited by several earthquakes. The simulation was carried out in the longitudinal direction of the building for the $1940 \mathrm{E} 1$ Centro (N-S component) earthquake. The natural periods of vibration for the first eight modes in this direction were: $5.38,1.98$, $1.19,0.85,0.66,0.54,0.46,0.40$ seconds respectively. The structure remained entirely elastic throughout the thirty second duration of the earthquake. This was not surprising as the tower was sized using the $1940 \mathrm{E} 1$ Centro ( $\mathrm{N}-\mathrm{S}$ component) as the design earthquake at yield level. A typical floor plan of the tower is included as Figure 4. Figure 3 represents a transverse section through the tower. Plan dimensions of the tower are 220 ft $\times 120 \mathrm{ft}$. The height above the surrounding plaza is $650 \mathrm{ft}$. In the longitudinal direction only the exterior frames participate in resisting lateral forces on the structure. Three dimensional or box action was considered in which the end wall frames participate in resisting the overturning moments induced by lateral loads in the side wall frames. A suitable linking technique was devised at the corner column to permit the transfer of vertical load into the transverse end wall frames without exerting any fictitious rotational restraints or transmitting any lateral shears around the corner. Owing to symmetry, only one-quarter of the structure was analyzed. The transverse direction was modelled identically except for the inclusion of six-two bay interior moment resisting steel frames below the 28th floor. The stiffness parameters of the structure were evaluated on a center line to center line basis.

\section{Excitation}

The seismic excitation was applied along each of the major axes of the building in turn. A total of nine earthquake records were used to induce varying degrees of vibration in the structure. All of the simulated earthquake motions (Jennings, Housner and Tsai $1968)^{6}$, modelling ground shaking of the order expected from earthquakes of magnitude 4.5 through 8.5 on the Richter Scale were utilized, plus the $1940 \mathrm{El}$ Centro record (7.2 magnitude).

For the simulation run, the time interval of integration of the modal equations of motion was set at $1 / 40$ second, thus generating histories of the relative lateral displacements 


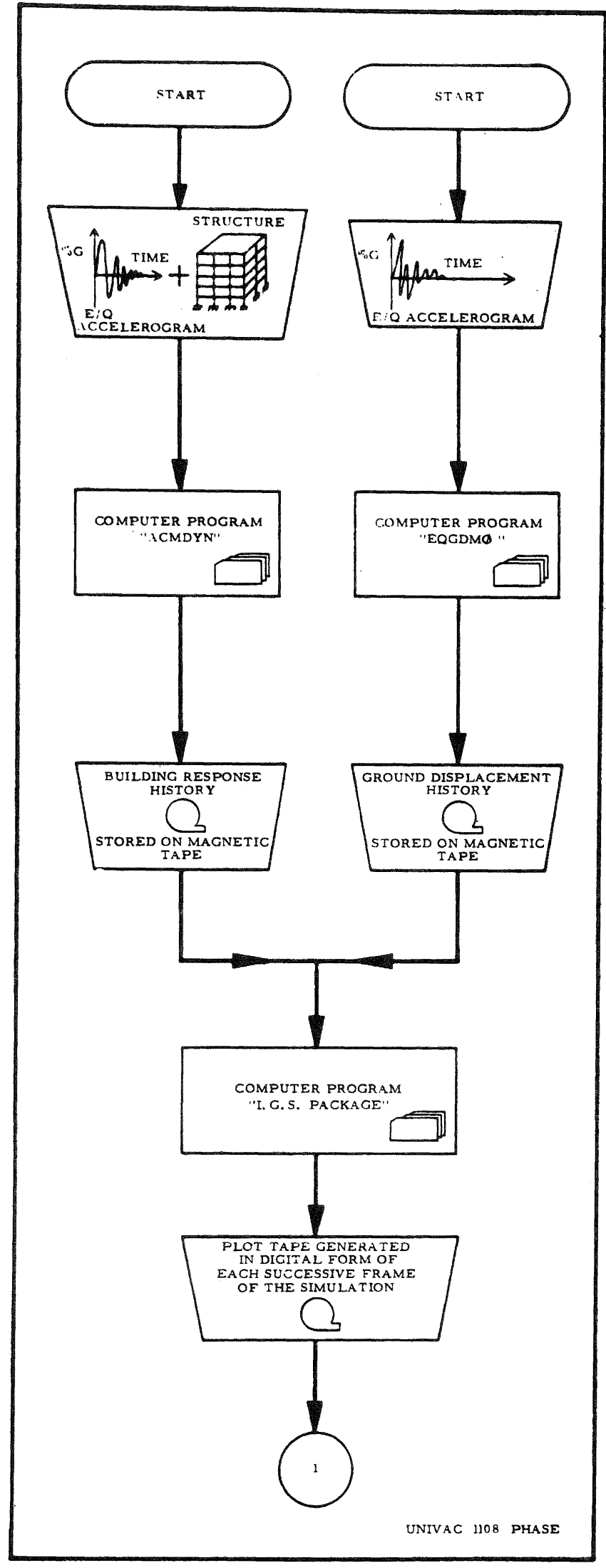

FIGURE 2 a - ANALYSIS PHASE

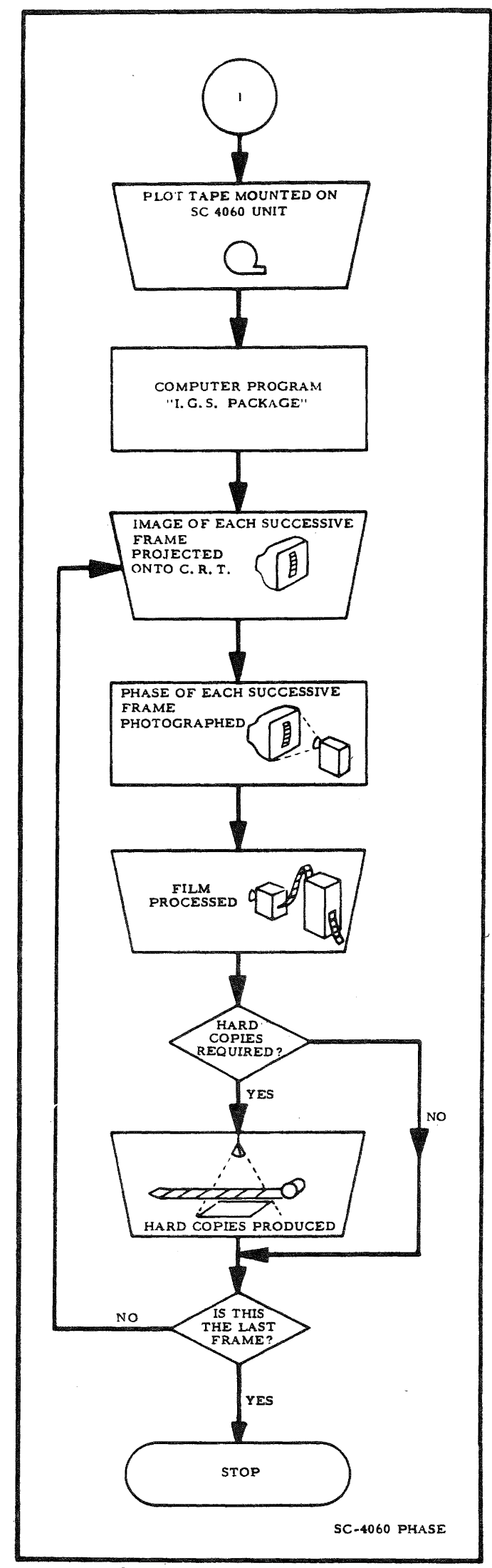

FIGURE'2b - SIMU LATION PHASE 
52 STORY TOWER

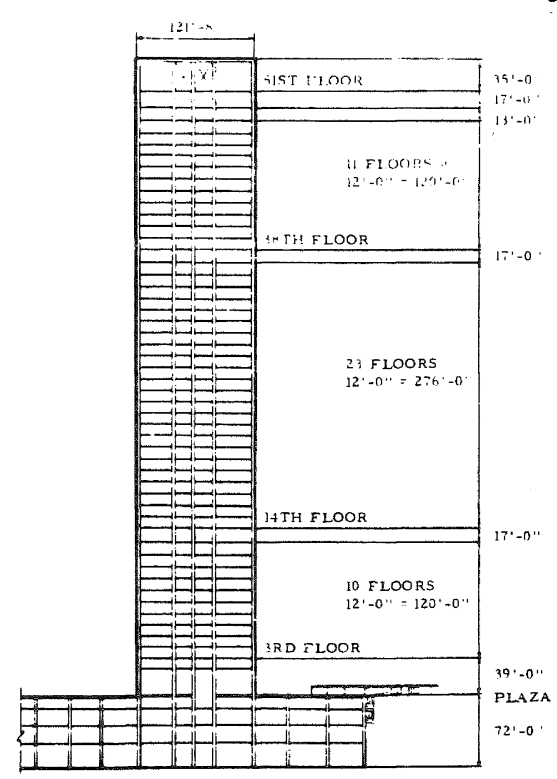

FIGURE 3

TRANSVERSE SECTION

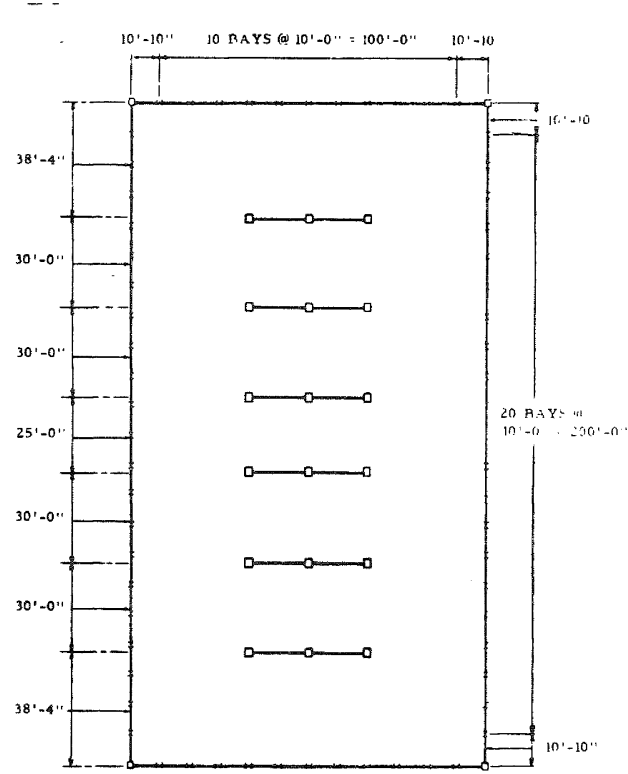

FIGURE 4

TYPICAL FLOOR FRAMING of the 1st, 2nd and 3rd modes individually and for all first 8 modes combined at each floor level at the same time interval. These four time histories were then sequentially stored on magnetic tape.

\section{Program Description}

An abstract of the computer program "ACMDYN"4 follows. It is included to describe the extensive capabilities of the program.

$\begin{array}{ll}\text { TITLE: } & \text { ACMDYN } \\ \text { TYPE: } & \text { Analytical } \\ \text { COMPUTER: } & \begin{array}{l}\text { Univac } 1108\left(131^{\mathrm{k}} \text { core }\right), \\ \text { CDC } 6600\left(131^{\mathrm{k}} \text { core }\right)\end{array} \\ \text { LANGUAGE: } & \text { Fortran V } \\ \text { CAPACITY: } & 70 \text { Stories, } 30 \text { bays, unlimited } \\ & \text { number of different frames }\end{array}$

\section{PURPOSE AND DESCRIPTION}

"Elastic, two-dimensional dynamic lumped mass analysis of steel or concrete, braced or unbraced orthogonal frames, with or without shear walls, using the normal mode method. $(2 n+1)$ degrees of freedom are allowed at each story, where $n=$ no. of joints in frame (a any story. Three dimensional or box action may be considered. Beams and/or columns may be either prismatic or non-prismatic, pinned or restrained at either or both ends. Diagonal bracing is limited to pin-ended members. Axial column shortening, shear deformations and finite joint size effects are considered. Allows for lateral exterior restraints to be applied at any story. Obtains time history responses for absolute floor accelerations, drift, inter-story drift, story shears and story overturning moments and maximizes on each response. Constant damping in each mode. Determines periods and mode shapes of structure. Establishes individual percentage modal contributions of each of the maximum responses. Determines maximum member loads and stress levels. Establishes maximum vertical displacements and rotations at each joint and determines the maximum slope coefficient for each girder. Handles multiple earthquake per run. Any number of problems may be solved in each run. Plot options for plotting maximum responses are incorporated. Evaluates steel tonnage when applicable."

The lateral displacements computed by "ACMDYN" are those that are relative to base. To achieve a meaningful simulation, it was necessary to obtain and portray the absolute lateral displacement histories for each story. This was accomplished by generating the time history of the ground displacement at the $1 / 40$ second interval and algebraically summing it to the corresponding time history for the relative displacements. As Figure 2 indicates, the computer program "EQGRMO" 5 performed the necessary integration procedures. By taking the variable interval earthquake accelerogram 
100

of the 1940 El Centro (N-S component) earthquake and executing successive integrations to yield first the ground velocity and then the ground displacement history, a magnetic tape was generated, storing the base motion record at a $1 / 40$. second time interval. The program incorporates an integration routine based on a combination of Simpson's and Newton's $3 / 8$ rules. A plot was obtained on a constant line ink plotter to verify the accuracy of the base motion.

\section{SIMULATION PHASE}

\section{General}

The simulation was effected by utilizing the Integrated Graphics Software (I.G.S.) System in conjunction with a Stromberg-Carlson 4060 computer recorder. The I.G.S. package is a comprehensive system comprising a library of subroutines to provide various display functions. It is Fortran-oriented, although it may be called from assembly language, Cobol, PL/1 or any other symbolic language compatible with the subroutine linkage conventions. It was developed as a co-operative effort between Stromberg Data Graphics Incorporated and the Rand Corporation. In 1968, the Naval Weapons Center at China Lake, California, released a Univac 1108 version that included additional polar routines. This version allows the 1108 to accept data and graphic formatting instructions, to perform necessary scaling, conversions and translations, to create meta-language output and to write it onto magnetic tape or other output device. The meta-language information is then read by the product control unit ( $a$ DDP ST6 computer) in the S-C 4060 for conversion to the sequence of hardware commands required to produce the CRT graphic display, either a $16 \mathrm{~mm}$. or $35 \mathrm{~mm}$. film record and a hardcopy print of any or all frames as desired. Figure $2 \mathrm{~b}$ represents a diagrammatic flowchart of this simulation phase.

\section{Animation Technique}

The basic technique employed was one of animation. A plot of the tower configuration was generated and stored in meta-language on a magnetic tape, at a given point in time. The plot resulted from the superposition of the coincident ground displacement and the building response for each story. Each plot then constituted a frame in the final movie. The tower was represented as a frame and not simply as a single line. Floor levels were described and plotted. By programming the advance of the film, successive frames were generated for each point in time. The time interval between frames was selected as $1 / 40^{\text {th }}$ of a second. This was done to correlate the time interval between frames and the speed of a movie projector. At normal speeds, 24 frames/second are projected on a screen. By achieving this correlation, the frequency of the tower vibration was preserved in the screen image of the tower. This means that the motion of the image is in real-time.

\section{Purpose and Scale Factors}

Prime consideration during development of the simulation was devoted to the purpose for which the simulation was intended and also to the scale factors involved. In this instance, it was desirable to tailor the simulation for client, technical and general viewing. As such, several sequences were compiled using various scale factors. For technical presentations it was deemed important to have the motion of the screen image reflect the actual motion of the $650^{\prime}$ high building.

To achieve this, a magnification factor of 120 was required to be applied to the horizontal scale. Expressed in different terms a reduction scale of 120 was applied to the vertical scale. This was based on a $5^{\prime}$ high image. When projected to this image height, the lateral deflections, velocities, and accelerations are exactly those of the actual tower structure. This situation is represented by sequences 2 and 5 . For client viewing, sequence 1 shows the base motion scaled on the order of the actual ground motion for a projected image five feet in height. The building distortion is scaled to the building size which on this size image is of the order of $1 / 120$ of the actual building dimensions. This is intended to give the viewer the feel of the actual ground motion and yet show that in comparison with the building size, the lateral building distortions are barely perceptible.

Another sequence (sequence 3) was devised to illustrate the concept of modal participation. The complex distortion of a building when elastically vibrating under any set of dynamic forces represents the summation of several simple curves or mode shapes. Associated with each mode shape is a natural period of vibration. The degree to which these independent modes are excited depends on the particular forcing function. At any given point in time at a given story, the lateral displacement of the tower can be identified as having contributions from all of the particpating modes. This was illustrated by displaying the first three modes of vibration on a single frame of the movie. The magnification factor was reduced to 67 for this sequence, simply to accommodate the three separate images. Each image depicts a separate coincidental mode of vibration. This entire sequence was repeated as sequence 4 , to include several interrupt features. By generating a number of identical frames on the plot tape, a stop-action feature was introduced. Four such features were incorporated as shown in Figure 5. 


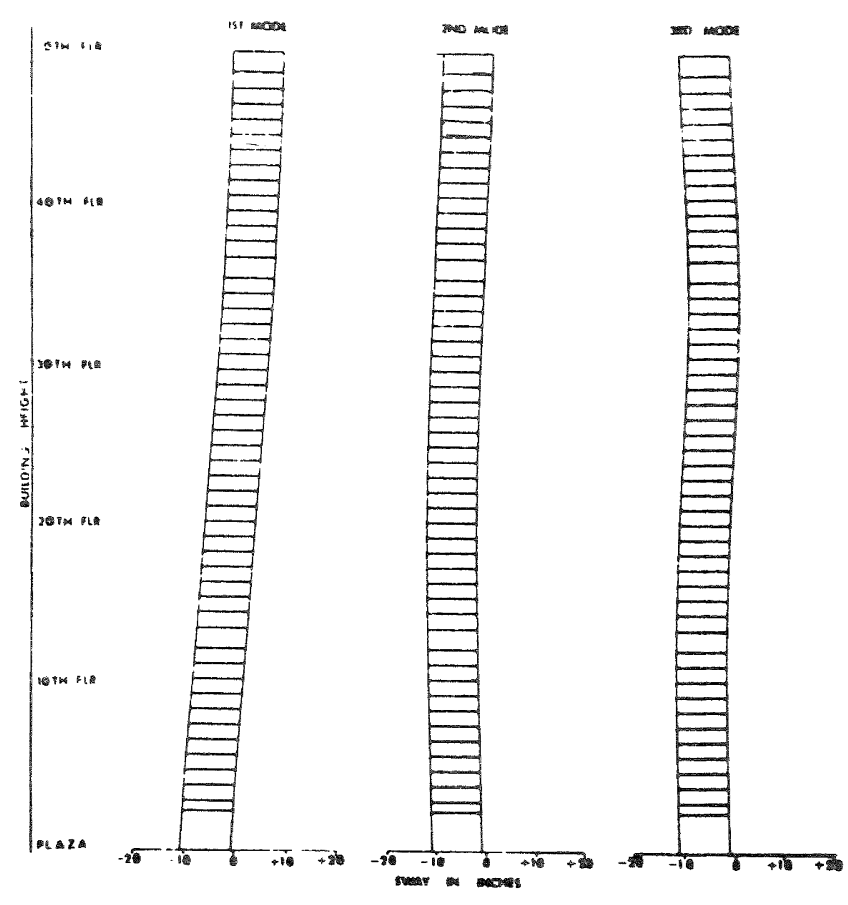

FIGURE $5 \mathrm{~A}$

MODAL PARTICIPATION AT 3.6 SECS.

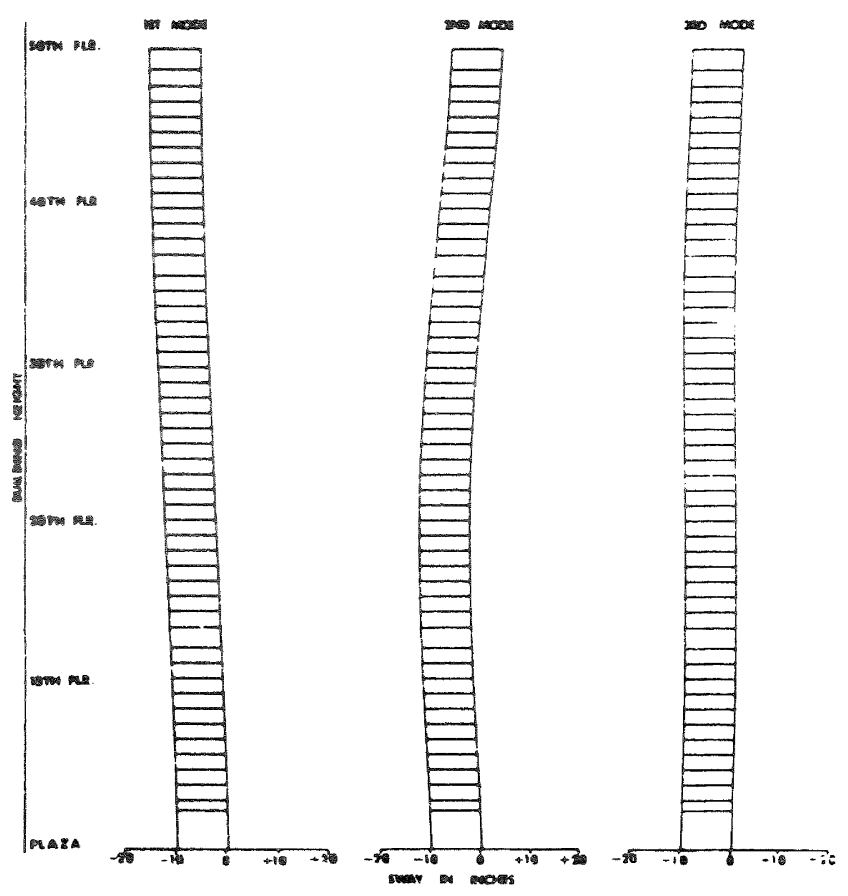

FIGURE 5C

MODAL PARTICIPATION AT 6. 4 SECS.

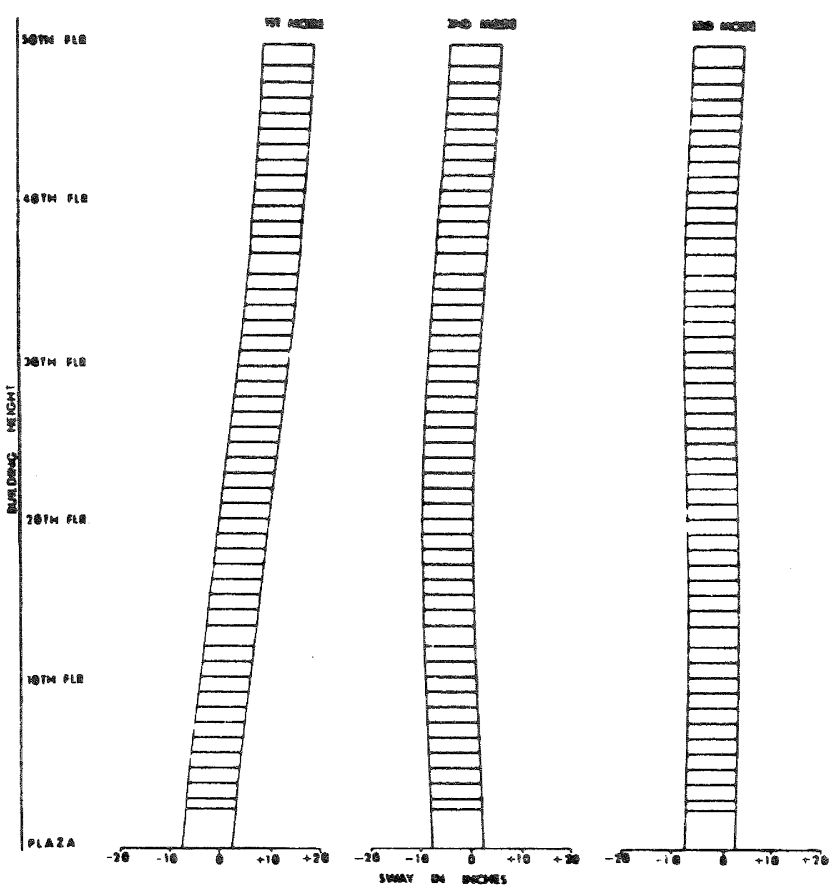

FIGURE 5B

MODAL PARTICIPATION AT 4.0 SECS.

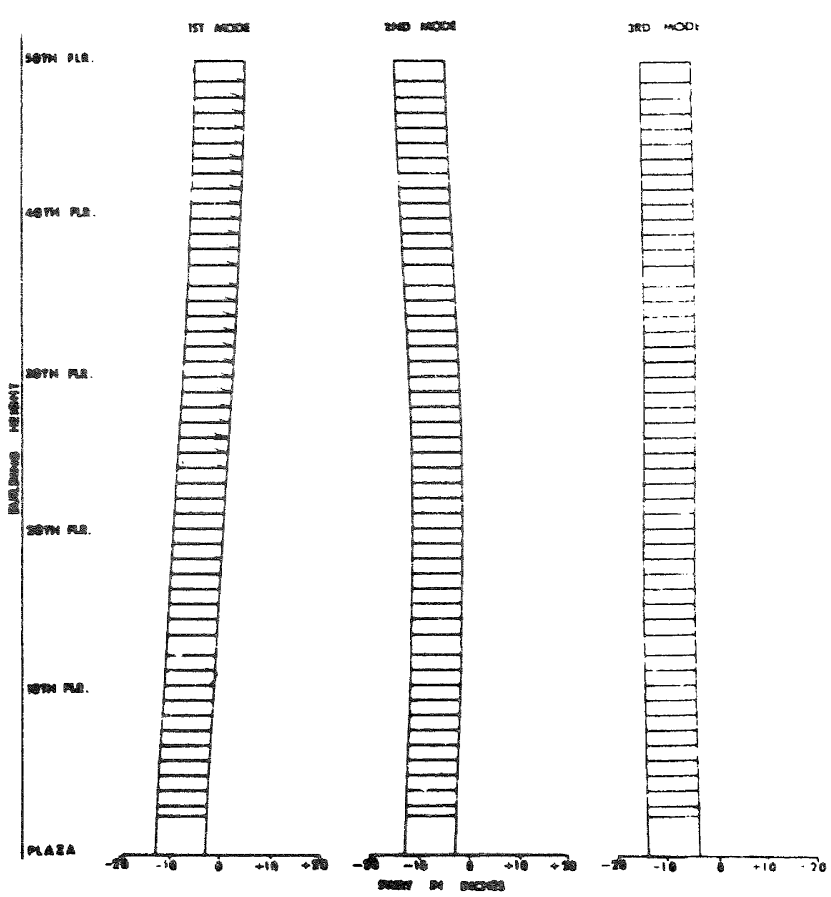

FIGURE 5D

MODAL PARTICIPATION AT 9.6 SECS.

FIGURE 5

SIMULATED EARTHQUAKE RESPONSE OF A 52 STORY TOWER

FOR THE MAY 19.40 EL CENTRO (NS COMPONENT) GROUND MOTION. 
102

Figure 5a indicates the largest relative to base 3 rd mode contribution. This occurs on the 13th floor at 3.5 seconds.

$\begin{array}{ccc}\text { lst mode contribution }+2.8^{\prime \prime} & (+350 \%) \\ \text { 2nd mode contribution }-1.1^{\prime \prime} & (-138 \%) \\ \text { 3rd mode contribution } & \frac{-0.9^{\prime \prime}}{} & (-112 \%) \\ \sum(1+2+3) & +0.8^{\prime \prime} & \end{array}$

The actual displacement relative to base, at this time, of all lst eight modes $=+0.8 "$. This does not indicate that higher modes are neglible in themselves, rather that their summation is.

Base displacement at 3.5 seconds $=-6.0^{\prime \prime}$

Figure $5 \mathrm{~b}$ shows the modal participation at 4.0 seconds. The largest 1 st mode displacement relative to base occurs at this time and, of course, occurs at the roof. The maximum roof deflection and the maximum base overturning moments also occur at this time. This illustrates that both of these parameters are essentially governed by the lst mode response. Breakdown:

Ist mode contribution 2nd mode contribution 3 rd mode contribution

$$
\sum(1+2+3)
$$

\begin{tabular}{ll}
$+15.8^{\prime \prime}$ & $(+82 \%)$ \\
$+2.7^{\prime \prime}$ & $(+14 \%)$ \\
$+0.7^{\prime \prime}$ & $(+4 \%)$ \\
\hline$+19.2^{\prime \prime}$ &
\end{tabular}

Base displacement at 4.0 seconds $=-3.2^{\prime \prime}$

Figure $5 c$ illustrates the largest 2nd mode participation. Occuring at 6.4 seconds at the 21 st floor, the combined displacements of the lst, 2nd and 3rd modes (rel. to base) is -5.4" which again approximates the displacement considering the first 8 modes of vibration.

\section{Breakdown:}

$\begin{array}{ccc}\text { 1st mode contribution } & -2.9^{\prime \prime} & (+54 \%) \\ \text { 2nd mode contribution } & -2.7^{\prime \prime} & (+50 \%) \\ \text { 3rd mode contribution } & +0.2^{\prime \prime} & (-4 \%) \\ \qquad(1+2+3) & -5.4^{\prime \prime} & \end{array}$

Base displacement at 6.4 seconds $=-5.4^{\prime \prime}$

Figure 5d depicts the opposing nature of the lst and 2 nd modes at the roof level. Occuring at 9.6 seconds the breakdown is:

$\begin{array}{ccc}\text { 1st mode contribution } & +8.2^{\prime \prime} & (+152 \%) \\ \text { 2nd mode contribution } & -2.0^{\prime \prime} & (-37 \%) \\ \text { 3rd mode contribution } & \frac{-0.3^{\prime \prime}}{(-5 \%)} & (-5 \%) \\ \sum(1+2+3) & +5.9^{\prime \prime} & \end{array}$

Base displacement at 9.6 seconds $=-8.8$ "

Other maxima of the response are;

1. Maximum absolute displacement of roof occurs at 2.4 seconds $=23.4^{\prime \prime}$

2. Maximum ground displacement occurs at 2.6 seconds $=-11.4^{\prime \prime}$

3. Final ground displacement $=-7.5^{\prime \prime}$

The ground displacement history depends on the particular version of the El Centro earthquake record used and on the type of baseline correction applied. For the purposes of this simulation the accuracy of the digitization or the baseline correction was not considered significant.

To complete the movie, a repeat sequence (sequence 5) was added showing the combined motion of ground and tower at the same scale factor of 120. Each configuration in Figure 5 was drawn directly on a constant line ink plotter from stored data on the plot tape.

\section{EVALUATION OF THE ANALYSIS AND SIMULATION}

\section{Benefits to the Client}

The benefits of this type of analysis and simulation to a client are significant. Some of these are enumerated as follows:

- Identifies the degree to which a structure will adequately resist earthquake shaking.

- Determines essential information which can form the basis of an earthquake risk analysis. Such a risk analysis can result in possible savings in earthquake insurance premiums. A client can either negotiate lower insurance rates or alternatively limit his coverage to some value less than the value of his total investment. In general, an earthquake risk analysis will indicate the possibility, or otherwise, of either partial or total collapse, based upon the maximum possible earthquake ground shaking that authorities believe could occur at the building site. It will also identify damage cost estimates for various probabilities of ground motions associated with a given period of time. It may, if the situation permits, establish an upper monetary limit of the damage, usually excluding fire risk, that may be sustained by the building concerned.

- Establishes potential problem areas within a structure, possibly affecting location of equipment. For example, computer installations, sensitive instrumentation, etc.

- Allows a safer structure to be designed for little or no extra cost. This, for example, reduces the usual liability risks involved and minimize business interruption resulting from a severe earthquake. It can form a basis of negotiation for reducing liability and B.I. earthquake insurance premiums and deductibles.

- Produces a structure that has been designed to reduce the level of human discomfort during a severe earthquake. 


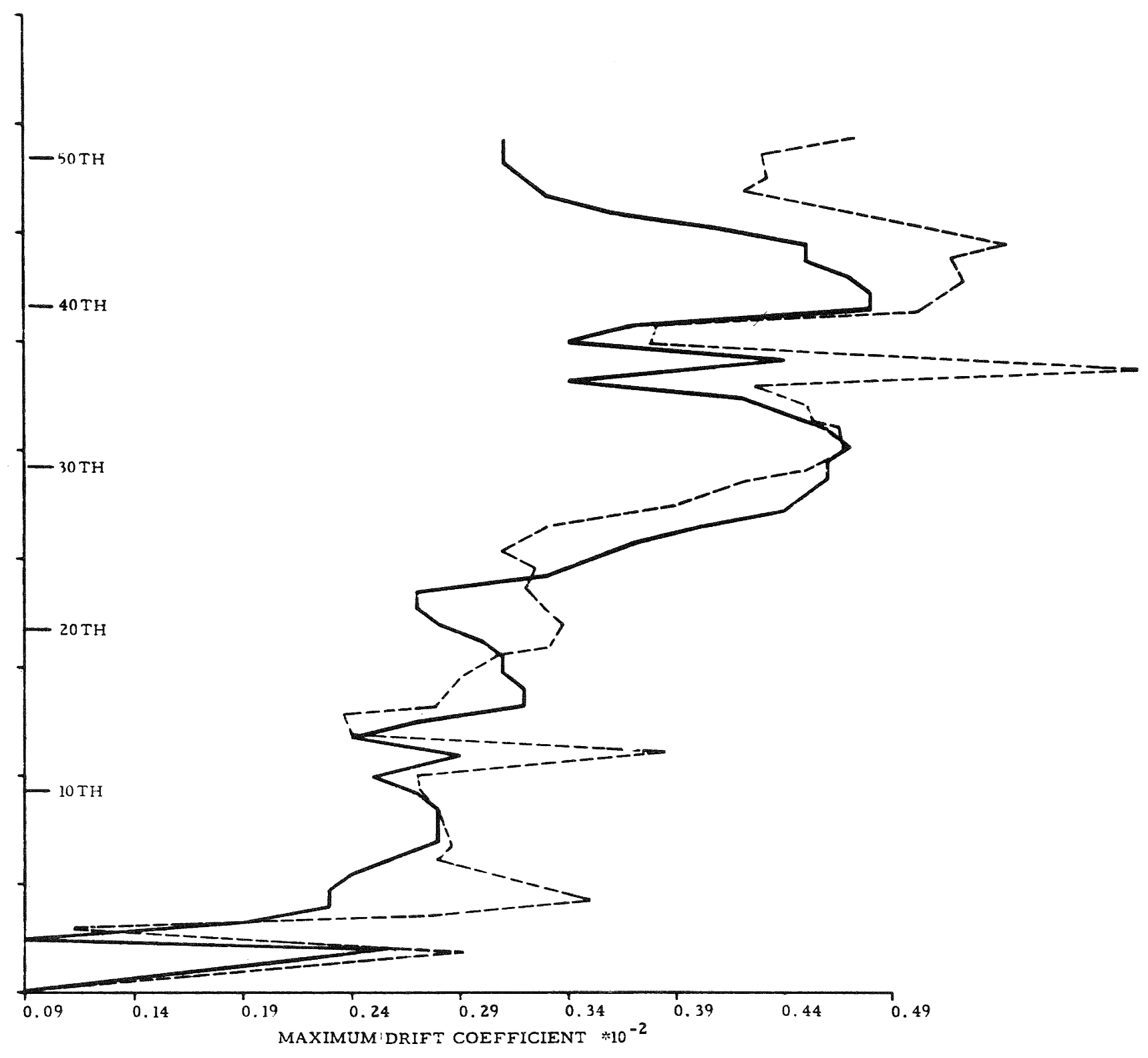

FIGURE 6

DRIFT COEFFICIEN I' 


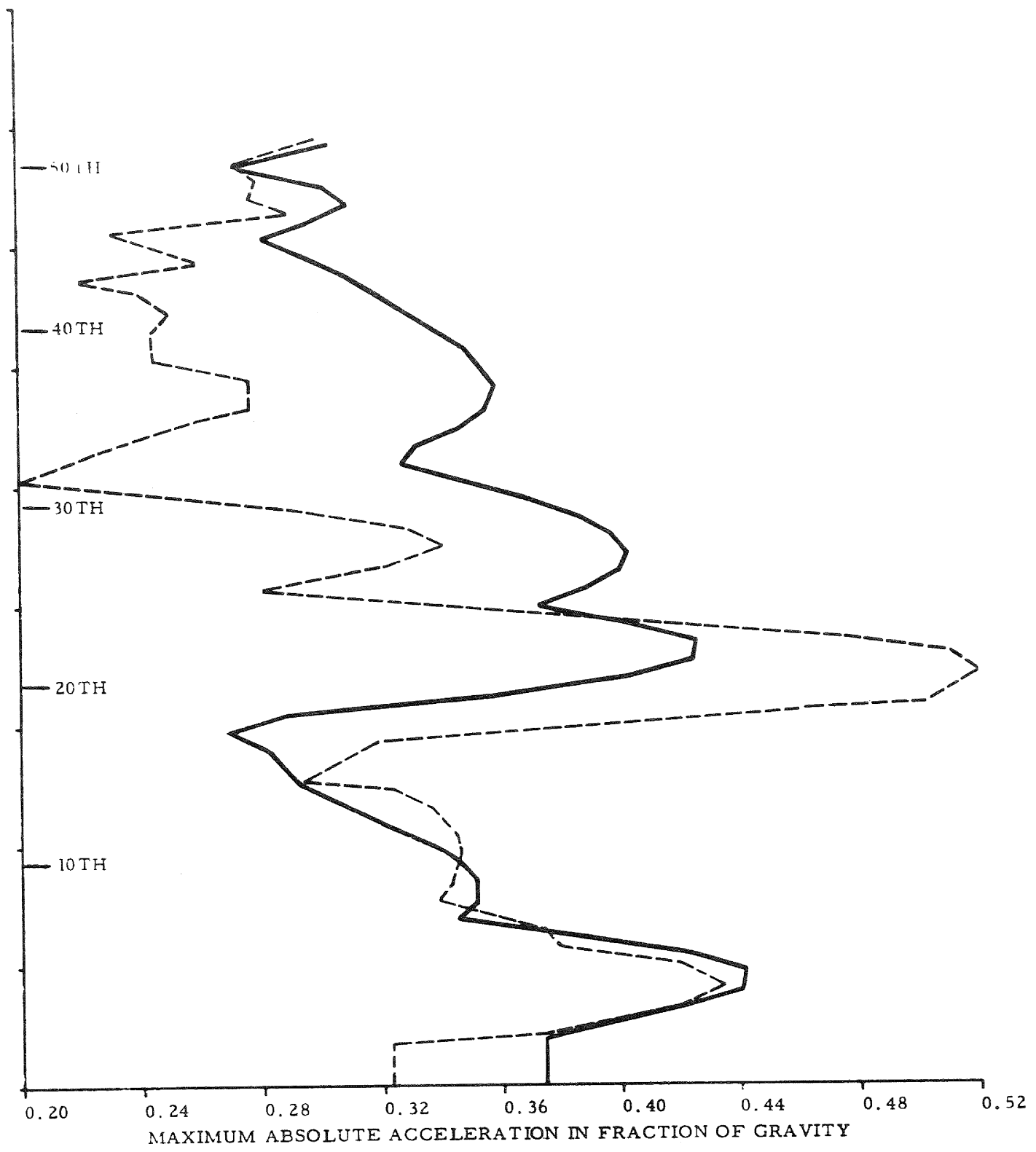

FIGURE 7

ACCELERATIONS 
Provides a visual graphic assurance of the stability of a client's structure during any earthquake motion.

\section{Benefits to the Structural Engineer}

The use of this approach results in many benefits to the structural engineer. These advantages are summarized below:

- Affords a check on manual sizing calculations. Figure 6 has been included to illustrate this. The two curves represent a beforeafter portrayal of the variation of the maximum drift coefficient over the height of the tower for the $1940 \mathrm{El}$ Centro earthquake. The large peaks in the dashed curve at the 14th and 38 th floors indicate sizing errors in the vicinity of the mechanical equipment floors. These errors, previously undectected, were graphically displayed. The solid curve represents the final corrected plot of the drift coefficient variation.

- Points out the essential dynamic characteristics of the structure, for example it detects the presence or otherwise of whiplash effects.

- Allows the engineer to control undesirable responses. To illustrate this, Figure 7 represents a plot of the maximum lateral absolute accelerations, which can be considered as a measure of the human response, for each story in the structure, when vibrating under the influence of the $1940 \mathrm{El}$ Centro earthquake. The excessive acceleration of the 21st floor shown in the dashed curve, is due to a large second mode contribution. Final tailoring of the structure resulted in the elimination of this peak value as indicated by the solid line. The prime reason it was deemed necessary to correct this situation was because of its consistent appearance in most of the acceleration responses for other earthquake excitations.

- Enables the engineer to tailor his structure to a consistent uniform strength over the full height of the structure.

- Identifies the degree of drift control achieved for different levels of earthquake intensity, thereby establishing clearance requirements for exterior solid panelling etc.

- Permits the engineer to design, for little or no extra cost in materials, a structure to withstand, adequately, earthquake forces far in excess of code minimums.

- Allows the engineer to grasp the concept and the degree of modal participation in an elastic dynamic response.

- Enables the engineer to get a visual "feel" for his structure as well as a numeric one.

\section{CONCLUSIONS}

The techniques involved in both the analysis and simulation phases as described in this paper are well established and the necessary computer software packages to implement them, are generally available. The availability of, and easy access to the large digital computer has enhanced the practicability of these analysis and simulation techniques, the application of which could possibly be extended to the field of wind dynamics for high rise structures. The cost factors involved are not exorbitant and are not, in general, sufficient to prevent their frequent use. Thus, considering the advantages enumerated in the evaluation summary, the use of these techniques in the seismic design of all structures is to be recommended.

\section{ACKNOWLEDGEMENTS}

The co-operation of $\mathrm{E}$. L. Wilson of the University of California (Berkeley), in making the computer program "FRMDYN" available to Albert C. Martin and Associates, is gratefully acknowledged. "FRMDYN" formed the basis of the computer program "ACMDYN". Appreciation is given to Albert $C$. Martin and Associates for providing the resources and support for this research and development effort.

The encouragement and suggestions of E. J. Teal, Partner and Director of Structural Engineering at Albert C. Martin and Associates is acknowledged.

\section{REFERENCES}

1) Merchant, H. C., and Hudson, D. E., "Mode Superposition in Multi-degree of Freedom Systems Using Earthquake Response Spectrum Data". Bulletin of the Seismological Society of America, Vol. 52, No. 2, April 1962, pp. $405-416$.

2) Shepard, R., "Some Limitations of Modal Analysis in Seismic Design". Bulletin of the New Zealand Society for Earthquake Engineering, Vol. 2, No. 3, Sept. 1969, pp. 284-288.

3) Jennings, P. C., "Spectrum Techniques for Tall Buildings". Proceedings of the Fourth World Conference on Earthquake Engineering, Santiago, Chile. Jan. 1969.

4) Martin, Albert C. and Associates, "Computer Program - ACMDYN". ACMA Program Library, Los Angeles, California.

5) Martin, Albert C. and Associates, "Computer Program - EQGDMO". ACMA Program Library, Los Angeles, California. 
106

6) Jennings, P.C., "Simulated Earthquake Motions". Proceedings of the Fourth World Conference on Earthquake Engineering, Santiago, Chile. Vol. I, Jan. 1969, A-1, pp. 145.

APPENDIX - NOTATION

The following symbols are used in this paper:

$[M]=$ diagonal matrix of succesive story masses for a lumped mass analysis.

$[\mathrm{C}]=$ damping coefficient matrix.

$[\mathrm{K}]=$ lateral stiffness matrix.

$\{\ddot{y}\}=$ absolute acceleration vector.

$\{i \mathfrak{u}\},\{\dot{u}\},\{\mathrm{u}\}=$ relative to base lateral

acceleration, velocity and displacement vectors respectively.

$\{M\}=$ vector of successive story masses.

$\ddot{y}_{S}(t)=$ time varying ground acceleration.

$\mathrm{W}_{\mathrm{n}}$ = natural circular frequency of vibration for the $n^{\text {th }}$ mode.

$\mathrm{C}_{\mathrm{p}}$ = fraction of critical damping in the $n^{\text {th }}$ mode.
$\ddot{A}_{\mathrm{n}}, \dot{\mathrm{A}}_{\mathrm{n}}, \mathrm{A}_{\mathrm{n}}=$ modal amplitudes of acceleration, velocity, and displacement for the $\mathrm{n}^{\text {th }}$ mode, relative to base.

$$
\mathrm{M}_{r}=r^{\mathrm{th}} \text { mass. }
$$

$\emptyset_{\mathrm{rn}}=$ normalized characteristic displacement at the $r^{\text {th }}$ mass for the $n^{\text {th }}$ mode.

$j=$ total number of masses (stories) in the structure.

$\Phi=$ square matrix containing all the normalized eigenvectors such that the $n^{\text {th }}$ column corresponds to the $\mathrm{n}^{\text {th }}$ mode. 